IZA DP No. 6097

Adjusting to Skill Shortages:

Complexity and Consequences

Joshua Healy

Kostas Mavromaras

Peter J. Sloane

October 2011 


\title{
Adjusting to Skill Shortages: Complexity and Consequences
}

\author{
Joshua Healy \\ NILS, Flinders University \\ Kostas Mavromaras \\ NILS, Flinders University \\ and IZA \\ Peter J. Sloane \\ NILS, Flinders University, \\ Swansea University and IZA
}

\section{Discussion Paper No. 6097 \\ October 2011}

\author{
IZA \\ P.O. Box 7240 \\ 53072 Bonn \\ Germany \\ Phone: +49-228-3894-0 \\ Fax: +49-228-3894-180 \\ E-mail: iza@iza.org
}

\begin{abstract}
Any opinions expressed here are those of the author(s) and not those of IZA. Research published in this series may include views on policy, but the institute itself takes no institutional policy positions.

The Institute for the Study of Labor (IZA) in Bonn is a local and virtual international research center and a place of communication between science, politics and business. IZA is an independent nonprofit organization supported by Deutsche Post Foundation. The center is associated with the University of Bonn and offers a stimulating research environment through its international network, workshops and conferences, data service, project support, research visits and doctoral program. IZA engages in (i) original and internationally competitive research in all fields of labor economics, (ii) development of policy concepts, and (iii) dissemination of research results and concepts to the interested public.
\end{abstract}

IZA Discussion Papers often represent preliminary work and are circulated to encourage discussion. Citation of such a paper should account for its provisional character. A revised version may be available directly from the author. 


\section{ABSTRACT}

\section{Adjusting to Skill Shortages: Complexity and Consequences*}

Skill shortages are often portrayed as a major problem for the economies of many countries including the Australian economy. Yet, there is surprisingly little evidence about their prevalence, causes and consequences. This paper attempts to improve our understanding about these issues by using econometric methods to analyse the Business Longitudinal Database, an Australian panel data-set with information about skill shortages in small- and medium-sized businesses during 2004/05. We use this information to: (1) explore the incidence of skill shortages and the business attributes that are associated with them; (2) identify which businesses face more complex skill shortages, as measured by the number of different causes reported simultaneously; and, uniquely, (3) examine how this complexity affects businesses' responses to skill shortages and aspects of their subsequent performance. We show that complex skill shortages are more likely than simpler (singlecause) skill shortages to persist and to trigger defensive responses from businesses. We reject the conception of skill shortages as a homogenous phenomenon, and demonstrate the importance of distinguishing between skill shortages according to whether they have simple or complex causes.

JEL Classification: J0, J20, J23, J24

Keywords: $\quad$ skill shortages, small medium enterprises

Corresponding author:

Kostas Mavromaras

National Institute of Labour Studies

Flinders University

GPO Box 2100

Adelaide, South Australia 5001

Australia

E-mail:k.mavromaras@flinders.edu.au

\footnotetext{
${ }^{*}$ This paper draws from a study undertaken for the National Centre for Vocational Education Research (NCVER) by the National Institute of Labour Studies, Flinders University. See Healy J., Mavromaras K. and Sloane P.J., Skill Shortages: Prevalence, Causes, Remedies and Consequences for Australian Businesses. Final Report, September 2011. All authors share equally the first authorship of the paper.
} 


\section{Introduction}

From time to time employers in a number of countries refer to the difficulties they have in recruiting labour of the requisite quality, even on occasion when the labour market is relatively slack. Yet academic work on this issue is relatively sparse and in particular little is known of the consequences of such situations. Despite the perceived importance of skill shortages in Australia, the literature is similarly lacking in detail. This is a result of both a lack of detailed statistics and difficulties surrounding the definition of a 'skill shortage'. With respect to definitions, there may be confusion in employers' minds over their ability to attract labour and the concept of existing skill gaps or deficiencies in current employment, which have more to do with training inadequacies than 'shortages'. With respect to data limitations, there are currently no representative national data on the duration of vacancies or vacancy/unemployment ratios for different occupations in Australia, thus precluding the production of a statistical series on the extent of skill shortages over time.

This study utilises a new data-set produced by the Australian Bureau of Statistics the Business Longitudinal Database (BLD) - which currently covers the financial years of 2004/05, 2005/06 and 2006/07. These years were characterised by steady growth in the Australian economy and by several signs of possible labour market overheating. The average unemployment rate was 4.9 percent between July 2004 and June 2007, the lowest rate since the 1970s (ABS, 2011). The BLD contains a panel of some 2700 small- and medium-sized enterprises (SMEs), each with up to 200 employees. Its purpose is to provide longitudinal information about the factors that contribute to, and inhibit, business performance. One potential inhibiting factor is the presence of skill shortages, as reported by respondents (who are usually business owners or senior managers). The presence of a skill shortage is only observed once for each firm, in the financial year 2004/05, but there are repeated observations of business performance in the two subsequent years, including a measure of sales derived from administrative records of the Australian Taxation Office (ATO).

Using appropriate econometric techniques, we use the BLD data to investigate:

1. The incidence and causes of skill shortages;

2. The strategies that businesses use to relieve them; and

3. The short-term consequences of skill shortages for business performance 
We note at the outset that the BLD question on skill shortages is limited to whether or not they exist in the mind of the respondent. We cannot say anything, for instance, about their severity in terms of the percentage of workers affected, which occupations are most affected, or whether there are skill gaps or deficiencies (see Section 2). The BLD does, however, have compensating strengths. Respondents are asked the reasons for their skill shortages and how they dealt with them. Uniquely, we have information on whether a lack of skilled workers was felt to have significantly hampered business performance. Finally, we are able to compare the performance of firms that do and do not report skill shortages, to test whether they produce deleterious effects, including reduced sales. We believe these findings will have relevance for other countries.

The paper has the following structure. Section 2 briefly reviews the relevant literature. Section 3 describes the BLD dataset. Section 4 introduces and applies the multivariate regression estimation methods to examine the incidence of skill shortages, the responses to them, and their consequences for selected aspects of business performance. Section 5 concludes.

\section{Related Research}

Despite its common usage, what constitutes a labour or skill shortage is far from straightforward. Broadly speaking, a shortage implies a disequilibrium situation in which the demand for labour by an employer or group of employers is in excess of the supply of available workers at the ruling market wage. But what is the market wage? A situation in which a (low-wage) employer is not willing to pay the wage required to eliminate the shortage of workers should not be regarded as a true labour shortage. Further, recent literature emphasises the ubiquity of labour market monopsony, in which the labour supply curve facing the employer is upward sloping, even for many small firms. This means that in order to recruit extra workers the employer must raise wages, a situation which may well suggest to the employer that a labour shortage exists, when in reality supply and demand are in balance. However, raising pay to attract new workers may be too costly, if this means that the pay of existing employees must be raised also. Thus, for Australia, Mavromaras, Oguzoglu and Webster (2007) found that while skill shortages were associated with wage increases in the occupation of shortage, there was also evidence that wage increases in one 
occupation spread to other occupations in the same industry, with inflationary consequences.

Employers may also view as labour shortages internal skill deficiencies (where the skills of their existing workers are below some optimal level), or skill gaps (where firms' existing workers lack sufficient skills to do their jobs effectively). For example, Oliver and Turton (1982) point out that employers may identify as important a requirement to cope with non-routine technical problems, to work with little or no supervision or to have speed on the job and be reliable. Yet, these are very different in their implications from skill shortages, although they are often conflated in practice (see Green, Machin and Wilkinson, 1998, for the UK; Shah and Burke, 2005, for Australia). It is also likely that hiring standards may be adjusted according to the state of the labour market. When demand is buoyant, employers may be forced to take on workers who lack experience, other desired personal attributes, and adaptability. In contrast, when demand is depressed and labour is abundant, employers may raise their expectations and look for qualities beyond those required in terms of the technical capacity to perform the job (Richardson, 2007). This implies that in tight labour markets the number of under-educated and under-skilled workers is likely to increase, while in slack labour markets the number of over-educated or over-skilled workers is likely to do likewise. These imbalances will have implications for the likelihood of both internal and external training being offered as a response. What is acceptable in terms of hiring standards may vary, therefore, according to the stage of the business cycle. Similarly, the form of adjustment may be influenced by the cycle. Stevens (2007) analysed an unbalanced firm panel data-set for the United Kingdom over the period from 1982 to 1994 and found some support for the suggestion that non-wage adjustment is preferred when labour markets are tight, as under such circumstances it will be more costly and less effective to raise wages.

In Britain, where labour shortages have often been much higher than in other countries, several studies have examined different measures of labour shortage. In 1989, for example, no less than 31 percent of firms reported that their output was constrained by a shortage of skilled labour. Haskel and Martin (1993a) used the 1984 Workplace Industrial Relations Survey (WIRS) to relate skill shortages to vacancy duration, noting that when labour is in short supply firms must wait longer than normal and (or) search more actively in order to hire workers. They discovered that 
unionised firms and those offering profit-related pay suffered less than others from labour shortages. They found, however, no evidence of firms raising wages to eliminate labour shortages, although shortages did diminish when local unemployment was higher. In a separate paper, Haskel and Martin (1993b) argued that skill shortages lower output in at least two ways: first, by increasing hiring costs for skilled workers, which causes them to be replaced by less-skilled workers and, second, by increasing the bargaining power of skilled workers, which enables them to choose an easier pace of work. Using a panel of 81 3-digit industries for the period 1980 to 1986, they found that the increase in skilled labour shortages over this period reduced productivity growth by a not insubstantial 0.7 percent per annum. Haskel (2001) used data from the 1990 Workplace Employee Relations Survey (WERS) and the related 1991 Employee Manpower and Skills Practices Survey to investigate the links between technology and skill shortages in the United Kingdom. He found that skill shortages were higher for establishments that used advanced technology in the production process, in line with the skill-biased technological-change argument. In this study, skill shortages, hiring difficulties, and hard-to-fill vacancies were found to be closely related concepts. However, the correlations among them were somewhat low, lying between 0.3 and 0.4 .

These same datasets were analysed in rather more detail by Green, Machin and Wilkinson (1998), focusing not just on causes of skill shortages, but also on reasons for recruitment difficulties among establishments with hard-to-fill vacancies. They suggested that, while employers do not seem to have any difficulty in interpreting what is meant by the term 'labour shortage', this interpretation may differ from one employer to another. Many of them refer to motivational or attitudinal deficiencies, in relation to both existing and potential employees, suggesting that lack of social skills is an important component of the skill-shortage problem. These findings point to two shortcomings in the present literature: first, there are no adequate and widely-accepted measurements of skill shortage and, second, there is no consistent understanding among employers as to what they choose to classify as a skill shortage.

Finally, it is possible that firms can reduce the problem of skill shortages if they can gain a reputation for being a good employer. Using a company dataset of 204 German firms, Backes-Gellner and Tuor (2010) showed that firms can reduce vacancy rates by signalling to potential employees the good quality of their labour relations. Relevant 
aspects included apprenticeship training and systematic continuing-training programmes, which signal that firms are not reliant on poaching skilled labour from elsewhere; the presence of a works council, which signals job security and a good working environment; and the overall skill-intensity of the workplace, which signals a challenging and interesting environment. All three variables above are significant in reducing the vacancy rate.

Australia generally lacks data on the duration of vacancies or vacancy/unemployment ratios (the Beveridge Curve) for different occupations across the whole country. The Department of Education, Employment and Workplace Relations (DEEWR) produces data on the proportion of vacancies filled and on the number of suitable applicants per vacancy, as well as producing a regular publication, Skill Shortages Australia. These are based on the results of a (telephone) Survey of Employers who have Recently Advertised (SERA). It assesses the labour market for between 120 and 150 skilled occupations, mainly in the trades and professions. Whether the vacancy is filled is measured six weeks after advertising in the case of professional vacancies, and four weeks in the case of other occupations. However, the survey is not a random sample of employers and, as Coelli and Wilkins (2008, p.312) put it, 'the targeted nature of the survey instrument precludes the construction of quantitative estimates of skill shortages that reflect Australian employers overall'. One reason for this may be that the vacancies data are frequently duplicated and out-of-date. According to the National Audit Office Annual Report (2006), initially around 14 percent of vacancies were duplicated and over time the duplication rate rose to a much higher figure of 46 percent (ibid. p.17).

Despite the lack of reliable data, skill shortages are reported frequently and form the basis of a substantial part of Australian immigration policy, as partly reflected in visa sub-class 457 provisions. These have operated since the 1990s and enable employers to fill nominated skilled posts with overseas immigrants for (renewable) periods of up to four years, as well as allowing entry for secondary (family member) applicants, who are also allowed to work or study. By 2007/08, the number of primary grants had risen to a figure approaching 60 thousand and that of secondary grants to nearly 50 thousand. The Deegan Review (2008) put forward a number of proposals for reform, including minimum salary levels for migrants, English language requirements, an accreditation system for employers, and new lists setting out occupations for which 
temporary work visas would be granted. Deegan noted a number of specific cases of skill shortages, particularly in engineering, where the Association of Consulting Engineers Australia (ACEA) reported in its Skills Survey 2008 that, on average, twothirds of its members across Australia were either delaying projects, or even declining them altogether, because of a lack of workers; this was the third consecutive year that this had occurred. However, Deegan also suggested that the evidence in some other occupations was contradictory. Thus, while it was claimed that chefs, cooks, and truck drivers were in short supply, Australian Jobs 2008 (published by DEEWR) showed that unemployment in these occupations was above average or even at a relatively high level.

These examples are by no means atypical. Junankar (2009) observed that, although the resource-rich states of Western Australia and Queensland found it necessary to attract labour from other states, and employers in these states were demanding increases in quotas and temporary 457 visas, real wages in the two states were increasing more slowly than productivity growth. In addition, employers were advertising jobs which were temporary, casual, often with peculiar shifts, located in difficult environments, and which required workers to provide their own equipment. Precisely why employers refuse to improve the attractiveness of their employment conditions in the face of labour shortages remains something of a puzzle.

Apart from improving pay and conditions, the provision of training opportunities is an important element in alleviating shortages. As Richardson (2007) observed, this may not resolve the problem immediately, as training takes some time in certain occupations. Further, as Mitchell and Quirk (2005) observed, the efficiency of the training may not be perfect, as around 50 percent of those commencing trades training fail to complete it. There may also be problems relating to the poaching of trained labour, particularly where the skills imparted by the training are of a general nature.

\section{Data}

\subsection{The Business Longitudinal Database ${ }^{1}$}

Our data source is the Business Longitudinal Database (BLD), an Australian Bureau of Statistics (ABS) longitudinal data-set covering small and medium-sized enterprises. The scope of the BLD is restricted to businesses that are actively trading 
in the Australian economy, meaning those with an Australian Business Number $(\mathrm{ABN})$ that are remitting the Goods and Services Tax (GST). Businesses without employees are within its scope, but larger businesses (i.e. those with 200 or more employees) and businesses with complex structures (i.e. multiple ABNs) are excluded. Government departments and authorities, financial entities, and not-forprofit organisations are also outside the scope of the BLD.

The BLD contains data from two sources. The first is the Business Characteristics Survey (BCS), an annual mail-out survey conducted by the ABS. The BCS has a core set of questions that are asked of businesses repeatedly from year to year, to enable longitudinal analysis. To minimise respondent burden, much of this information is categorical, requiring simple 'yes or no' responses. The second data source for the BLD is administrative data, drawn mainly from Australian Taxation Office (ATO) records. The combination of these data sources yields much information about the factors associated with businesses' growth or decline.

Up to three waves of data are currently available from the BLD, covering the financial years from 2004/05 to 2006/07. 'Panel One', initiated in 2004/05, has information for 2732 firms and forms the basis of our analysis. ${ }^{2}$ It includes the key question on skill shortages asked of BCS respondents in 2004/05. The question (answered yes/no) was:

Did this business have skill shortages during the year to 30 June 2005?

A skill shortage was defined in the BCS as an 'insufficient supply of appropriately qualified workers available or willing to work under existing market conditions'.

Businesses that answered 'yes' to the skill shortages question were asked two further questions about their causes and responses. Both were multiple-response questions, allowing respondents to select more than one of the listed response options. First, businesses were asked: Were this business's skill shortages due to any of the following factors? A list of six response possibilities was provided, with the option to select 'other (please specify)'. Second, businesses were asked: How did this business address skill shortages during the year ended 30 June 2005? A list of seven response possibilities was provided, again with the option to select 'other (please specify)'.

A further area of interest is the persistence of skill shortages over time. Unfortunately, the question identifying a skill shortage was not repeated in the second or third waves of the BLD. As a proxy for skill shortage persistence, we identify businesses that 
selected 'Lack of skilled persons within the business' when answering the following question:

During [the year] did any factors significantly hamper this business in: either (a) the development or introduction of new or significantly improved goods, services, processes or methods; or (b) other business activities or performance?

\subsection{Descriptive statistics}

Table 1 presents data on the industry distribution of businesses that responded to the skill shortages question in the BLD. There is substantial variation in the incidence of skill shortages across the major industry divisions covered by the BLD. The incidence is higher in construction, which was experiencing boom conditions during 2004/05, and in lower-paid service sectors, such as hospitality and personal services. Property and Business Services has the lowest incidence of skill shortages in Table 1, despite anecdotal evidence of a particularly active real-estate sector at that time. This result may reflect the exclusion from the BLD of larger information technology and accounting firms which exceed its 200-employee size restriction.

$<$ Table 1 here $>$

The remaining analyses in this section focus on businesses that reported having had a skill shortage in 2004/05. Table 2 describes the reasons businesses nominated for their skill shortage. Multiple responses were permitted, and the responses have been ranked in descending order of reported frequency. The most common explanation, selected by 59 percent of businesses with skill shortages, was a requirement for specialised knowledge. A much less frequently reported set of reasons (each nominated by about one-quarter of businesses with skill shortages) ascribed responsibility to factors other than a deficit of required skills, such as slow recruitment processes, excessively high wage costs, and uncertainty on the part of the business about likely future demand for its product. About one in four businesses with skill shortages said that they were due to 'a lack of availability of adequate training', which may refer to either internal or external training inadequacies (or both).

Another way of using the data is to estimate the total number of reasons given by each business with a skill shortage. The bottom panel of Table 2 provides this information. Almost half (46 percent) of businesses affected by skill shortages attributed them to a single cause. We will refer to these businesses as having 'simple' skill shortages. 
One-third of businesses with skill shortages nominated two causes, and the remaining 20 percent selected three or more causes. We will refer to these two categories of business as having 'complex' skill shortages.

\section{$<$ Table 2 here $>$}

Table 3 shows how businesses with skill shortages responded to them. As in Table 2, the responses have been ranked by reported frequency. By far the most common action taken by businesses with skill shortages was to intensify work: extending the working hours of, or demands on, their existing workers (49 percent). This result is intuitive, as intensification is the most flexible, and thus most easily reversed, of the response options. By increasing the hours worked by current employees, businesses can also avoid the costs of raising wages or paying for new training. About one-third of businesses with skill shortages responded by subcontracting or outsourcing work, and about one-quarter elected to increase their provision of on-the-job or internal training.

The least common of the available response options was increasing the use of external training. This is a surprising result, as it implies that employers are reluctant to engage with the external training system, even when faced with self-reported skill shortages. Businesses affected by skill shortages were about twice as likely to increase wages or conditions of employment as they were to increase their use of external training. This result may reflect employers' concerns that, in conditions of labour shortage, newlytrained employees will be attractive poaching targets for rival businesses facing the same hiring constraints.

The bottom panel of Table 3 provides further evidence on how businesses responded to skill shortages. Over half (54 percent) of affected businesses used only one of the responses. Relatively few businesses with skill shortages (13 percent) used a barrage of three or more strategies when responding to them.

$<$ Table 3 here $>$

\subsection{Data limitations}

The datasets used in previous studies differ from the BLD dataset in several important ways. The BLD is limited to small- and medium-sized establishments, including some with no employees. We do not know whether a respondent actually advertised any 
vacancies over the 12-month period to which the skill shortages question pertains; those which did not advertise may not be well-informed about the true state of the labour market. The skill shortage question in the BLD is a simple yes or no question, namely whether the organisation had any skill shortages during the 2004/05 financial year. As mentioned earlier, it is possible that this concept may be confused either with skill gaps, a situation in which firms' existing workers do not have sufficient skills to do their jobs effectively, or with skill deficiencies, where existing skills are below some optimal level. As Green, Machin and Wilkinson (1998) noted, these concepts are quite different, although they are often conflated in practice. These other concepts are suggestive of a need for training or retraining.

The BLD does not allow us to establish the intensity of any skill shortage, such as the proportion of hard-to-fill vacancies or the average time taken to fill a vacancy. It is not possible to establish for which occupations the skill shortages have occurred; nor are the data split by gender. There are no questions on the extent to which immigrant workers are used to overcome skill shortages. Finally, the BLD excludes some industries, such as healthcare and education, which have many larger, publicly-funded organisations that are outside its scope.

Unlike any of the studies reviewed in Section 2, however, the BLD contains questions on how the respondents attempted to overcome the skill shortages problem and the impact that this may have had on business performance. These features make the data invaluable for assessing the overall impact of skill shortages. A further shortcoming, however, is that certain activities are observed only for the firms that reported having experienced a skill shortage. One example is the use of external training. Ideally, we would like to investigate the efficacy of external training by comparing the incidence and persistence of skill shortages in firms that did and did not train. However, because the use of external training is treated in the BLD as one of several possible responses to skill shortages, it is only available for the subset of firms that reported experiencing a skill shortage in 2004/05. Further limitations of this kind preclude other potentially useful comparisons from being undertaken with the BLD. 


\section{Multivariate analysis}

\subsection{Estimation methods}

The complex interplay between the causes of skill shortages, the responses they elicit, and their effects on business performance, can only be reflected with some accuracy through multivariate regression analysis. We use two estimation methods to analyse the incidence of skill shortages, the responses to them, and their persistence. We use a binary probit, to estimate if skill shortages are present or not within a business and, if so, whether they persist; and an ordered probit, to determine which types of businesses are more likely to encounter complex skill shortages. Our second estimation method is Ordinary Least Squares (OLS), where the variable of interest has a continuous coding, such as the change in the sales of a business from one year to the next.

There is an important caveat to the interpretation of our estimation results. Given that the BLD data on skill shortages was all collected during the first wave (2004/05), we cannot answer causal questions about which factors may have caused skill shortages to appear, or which causes may have triggered particular responses. We can only estimate associations. We have stronger causal evidence, however, in relation to the outcomes of skill shortages. This is because we have information from administrative data that are both independently collected and available for up to three years after the incidence of and responses to skill shortages were reported.

\subsection{The incidence of skill shortages}

The first question we seek to answer is: which businesses face skill shortages? Our data-set contains much information about the attributes of businesses that do (and do not) report skill shortages. This part of the analysis asks which variables are associated with the business having reported a skill shortage, and whether there are any patterns in the estimated associations.

Table 4 displays the full estimation results. The dependent variable is a binary indicator of whether or not the firm reported having a skill shortage in 2004/05. The reported marginal effects are estimates of the change in the probability of having a skill shortage associated with changes in each of the explanatory variables listed. For example, the marginal effect is 0.147 for the 'Agriculture, forestry and fishing' industry variable, indicating that businesses in the Agriculture industry are, on 
average, 14.7 per cent more likely to have had a skill shortage than businesses in the Manufacturing industry (the reference category). The $p$-values reflect the statistical significance of each marginal effect. Given the relatively small sample size and the large number of independent variables in the estimation, we regard $p$-values of less than 0.10 as sufficiently different from zero to be regarded as statistically significant.

$<$ Table 4 here $>$

Some clear associations are evident in Table 4. There are quite pronounced industry differences, but not all industries differ from Manufacturing (the reference category) in a statistically significant way. Businesses in Agriculture, Construction and Personal and Other Services are all significantly more likely to have reported skill shortages in 2004/05 than businesses in Manufacturing. Wholesale Trade is the only industry in which businesses are significantly less likely to have had skill shortages in 2004/05.

The reference category for the business-size variables is businesses with fewer than five employees. Businesses with five to 19 employees are 16.1 per cent more likely to have reported skill shortages, while firms with 20 to 199 employees are 25.8 per cent more likely to have reported skill shortages. The incidence of skill shortages, therefore, increases with firm size, even after other relevant factors have been controlled for within the multivariate regression framework. There are several explanations for this finding, including the fact that the increased specialisation present in larger firms increases the need for more specific skills. It should be noted, however, that this result may simply reflect the way the skill shortages question was asked when the data were collected, which only allowed the firm to report if there had been any skill shortage at all, irrespective of the number of occurrences. We, thus, cannot estimate whether there is a difference in the incidence of skill shortages per employee. It follows that the positive association reported for business size in Table 4 could also appear because of the size of the business.

We find that the type of legal entity of a business is not associated with its probability of reporting a skill shortage. Similarly, whether a business operates at multiple locations is not associated with its probability of reporting skill shortages. While the last two results may seem surprising, it is worth noting that the multivariate nature of the analysis suggests that other variables do a better job of explaining the variation in the incidence of skill shortages. The presence within a business of a single person 
who is responsible for major decisions increases the probability of facing skill shortages by 3.3 percent. This finding may be related to the quality and (or) style of management, including the effect of delegation in handling skill shortage problems. We find that whether a firm has a web presence is not associated with the probability of reporting skill shortages. This result suggests that firms with an online presence do not increase their visibility to potential recruits, or lower their search costs enough to significantly reduce their likelihood of facing skill shortages.

The level of sales within a business is not associated with the probability of reporting skill shortages. Again, it must be noted that the regression results suggest that other variables that we would expect to be associated with sales (e.g. number of employees) are probably doing a better job of explaining skill shortages. The implication is that it is not the level of sales that matters, but the number of employees. The age of the firm is also not associated with the probability of reporting skill shortages.

Market competition (at the product level) increases the probability of reporting skill shortages. The reference category is firms without a competitor in their market. Firms with one or two competitors are 13 per cent more likely to report skill shortages, while firms with three or more competitors are only marginally more likely to do so, at 13.9 per cent. There are many routes through which market competition may eventually influence skill shortages, including the depressing product-price effect of competition, which can have a depressing (derived) effect on wages. Lower wages can reduce the number of people who are willing to work for a business, which can be manifested as a skill shortage. Similarly, a more competitive market could also suffer from higher levels of skilled-labour poaching, which can lead to direct skill shortages as workers leave, and indirect skill shortages as employers become less willing to support general training.

\subsection{Complexity in the causes of skill shortages}

We next consider the attributes of businesses that are associated with the probability of encountering more complex skill shortages arising from multiple causes. Table 5 presents the results from an ordered probit estimation, where the dependent variable is the number of skill shortage causes reported simultaneously by each business and the independent variables include the business characteristics that were found, in the 
previous section, to be empirically important in determining the overall incidence of skill shortages. ${ }^{3}$

$<$ Table 5 here $>$

There are considerable differences in the complexity of skill shortages by industry. Agriculture, Construction, and Personal and Other Services are the industries in which businesses are most likely to report skill shortages with complex causes. Mining, Accommodation, Cafes and Restaurants, Transport and Storage, and Communication Services are also more likely to have businesses facing complex skill shortages (when compared with Manufacturing). Businesses in the Wholesale Trade are less likely to report multiple skill shortages.

With respect to the other model covariates, Table 5 reports that multiple causes are more likely to be present in larger firms. This result can be read in two ways, both of which are plausible. Larger firms will have more complex production processes, so that multiple causes would be more likely to affect them. Larger firms will also have higher turnover in absolute terms, so that different causes would be more likely to occur simply because of these larger numbers. It is interesting to note a positive association between complexity of skill shortages and the presence of a single leader in the firm. The association between the level of sales and the complexity of skill shortages is not statistically significant.

Finally, Table 5 reports that businesses operating in more competitive environments are more likely to encounter complex skill shortages. Note that the threshold for this result is between monopolists (businesses without competitors) and other businesses, since the coefficients on the two market structure variables (0.469 and 0.565) are not statistically significantly different from each other (the confidence intervals intersect). One interpretation of these results is that if businesses have to compete for customers with other businesses in the same product market, they will probably demand similar skills from potential recruits. If so, this would increase the likelihood of poaching, and reduce the probability that any single firm offers internal training, leading to a higher incidence of skill shortages (Table 4) and to more complex skill shortages (Table 5).

\subsection{Responses to skill shortages}

The BLD provides unique information, not only about the different causes of skill shortages but also the different responses. There is additional complexity in the data, 
since each firm is allowed to report multiple causes and multiple responses. Each cause may therefore trigger multiple responses, and each response may equally be the result of multiple causes.

The obvious scope for analysis with these data is limited in two ways, however. First, the questions about skill shortages and responses were only asked in the first of the three available waves of the BLD. The sequential process, whereby some causes are initially countered by one type of response, and only if that fails, by another, is thus not traceable in the data. This is a serious data shortcoming for modelling the nature of skill shortages. Second, for analysis of the responses to skill shortages, the useable sample size is restricted to those 407 firms that reported having had a skill shortage in 2004/05. With these caveats acknowledged, we now investigate businesses' responses to skill shortages.

We focus on the interplay between complexity in the causes of, and responses to, skill shortages. For many firms, there are complex and multiple causes of skill shortages that lead to multi-faceted responses. Modelling these interactions explicitly would exceed the capacities of our data-set for reasons already discussed. Instead, we analyse skill shortages complexity in a piecemeal fashion, by using a set of regressions each focusing on a different aspect of complexity.

We examine first whether the complexity of skill shortages, as measured by the number of causes present within each business, plays any role in determining their choice of response. ${ }^{4}$ We include on the right-hand side of the regression equation two indicator variables that reflect complexity in the causes of skill shortages. The first of these variables indicates firms for which two causes of skill shortages were reported simultaneously. The second variable indicates firms for which three or more causes of skill shortages were reported simultaneously. The base or reference category is firms that reported only one cause of skill shortages. We also control for several other firm attributes that were shown earlier to be empirically important in the incidence of skill shortages (i.e. business size, market structure, and industry sector). ${ }^{5}$ The logic of this approach follows that used previously in the estimation of complex causes (Table 5).

Table 6 shows clearly that most responses are sensitive to the presence of multiple causes of skill shortages, but that response sensitivity increases on some occasions between experiencing one or two causes of skill shortages, and on other occasions 
between one and three or more skill shortages. Longer working hours, which is the most common response to begin with, is estimated to be 14 per cent more likely to be used when a second cause of skill shortages is present (than when only one is present), and is a further 6.5 per cent more likely when three or more causes are present (bringing the total to 20.5 per cent). A similar picture is apparent for raising wages and (or) improving working conditions as responses to skill shortages.

This analysis suggests that longer hours and higher wages and improved conditions can be likened to a 'first line of defence' for firms experiencing skill shortages. The common characteristic of these responses is that they involve greater use of existing employees, which reduces the costs and uncertainty associated with hiring new staff or outsourcing. By responding internally, the firm retains managerial control and, to the extent that increased production also results in some extra profit for the firm, part of the extra profit is distributed to employees through increased wages and improved conditions.

\section{$<$ Table 6 here $>$}

Consider now the responses where the firm sacrifices some managerial control or retains none at all, and assumes additional risks. Table 6 suggests that an additional cause of skill shortages increases the probability of outsourcing by 10.8 per cent, but does not increase significantly the probability of short-term hires, reduced output, or using external training. The likelihood of outsourcing more than doubles when three or more causes of skill shortages are encountered (rising from 10.8 to 22.9 per cent), as does the likelihood of short-term contracts (rising from 6.2 to 14.1 per cent). The likelihood of external training being used remains very small and is not statistically significant. The likelihood of reducing output, which we regard as the most serious response, becomes significant only for firms reporting three or more causes of skill shortages. The implication is that firms take this response reluctantly, and only when confronted with complex, intractable skill shortages. There is however, a very sharp increase in the probability of reducing output for firms that do face complex skill shortages (it has the largest marginal effect in Table 6, at 23.8 per cent).

The intuition of the results in Table 6 is as clear as it is important. Complexity of the causes of skill shortages matters for how firms respond. Firms will initially respond by looking at their internal resources, by utilising and motivating more intensively 
their existing employees. When skill shortages become more complex, firms use their own workers still more and they pay them higher wages, but these responses have their limits. For example, moving from two to three or more causes of skill shortages only increases the probability businesses will raise wages and (or) conditions by 3 per cent. Firms then employ other strategies that often entail higher costs and uncertainty, such as outsourcing and short-term contracts. External training is not a response option that many firms exercise, presumably because they prefer to train their own workers and also expect new hires to arrive fully-trained. Finally, when all else fails, firms resort to cutting output. This appears to happen only when firms experience highly complex skill shortages, with a minimum of three reported causes. It is clear that firms will try many other responses before they resort to reducing output.

\subsection{Consequences of skill shortages}

The final section of our analysis considers the consequences of skill shortages. We consider two consequences in particular: whether skill shortages persist, and whether they influence the subsequent sales performance of businesses affected by them. Our analyses of whether skill shortages persist and affect sales are (implicitly) conditional on business survival. Since we are dealing with a sample of small- and medium-sized businesses, the possibility of closure is not remote, even over a three-year time period. We have explored elsewhere the relationship between business survival and the presence of skill shortages, and found that, after controlling for other relevant business attributes, there is no statistically significant association.

Do the businesses that report skill shortages manage to overcome them, or are they a continuing problem that they must endure? To address this issue, we utilise responses to a question that appears in the second and third waves of the BLD (i.e. 2005/06 and 2006/07), namely, whether a 'lack of skilled persons within the business' significantly hampered its performance. We estimate the associations between this variable and the presence and complexity of skill shortages as reported by businesses one or two years earlier (i.e. in 2004/05). Table 7 presents the results of the estimations.

$<$ Table 7 here $>$

We find clear evidence that skill shortages are mildly persistent. By comparison with a firm that had no skill shortage in 2004/05, a firm with a simple (single-cause) skill shortage was 21.2 per cent more likely to have reported a lack of skilled persons one 
year later (in 2005/06), and 10.4 per cent more likely to have done so two years later (in 2006/07). Note the substantial (10.8 percentage point) reduction in this probability between the two years, which suggests that simple skill shortages are less persistent. Two years after initially reporting a skill shortage, businesses that encountered simple types of shortages have, on average, managed to substantially reduce their probability of still reporting a lack of skilled persons. A similar point can be made in relation to businesses that faced skill shortages with two different causes. For these businesses, we again observe a tapering over time in the probability of a persistent lack of skills within the business (from 25.9 per cent in 2005/06 to 20.5 per cent in 2006/07).

Now compare these patterns with the results for businesses that faced more complex skill shortages (three or more causes) in 2004/05. For these businesses, the estimated probability of experiencing a persistent lack of skilled persons increases with time (from 34.5 per cent in 2005/06 to 40.2 per cent in 2006/07). This difference suggests that more complex skill shortages are quite distinct from simple, and even dual-cause, skill shortages, in their likelihood of persisting over time.

Our final question is whether the presence and complexity of skill shortages has any impact on affected businesses' subsequent growth and performance, as measured by total sales, when compared to (observably similar) businesses without skill shortages of any kind. The measure of sales growth that we use here is the difference between the natural logarithm of sales in 2005/06 and its equivalent in 2004/05. The estimation method is Ordinary Least Squares (OLS). Results are presented in Table 8.

$<$ Table 8 here $>$

Our results show that businesses with simple skill shortages have significantly higher sales growth than firms without skill shortages of any kind, after controlling for other differences in business attributes, such as size, market structure and industry sector. In contrast, businesses with dual-cause and more complex skill shortages perform much like comparable businesses without skill shortages. We find no statistically significant evidence that their subsequent sales performance is any better (or any worse) than that of similar businesses that are unaffected by skill shortages. While we cannot support the argument that simpler skill shortages directly cause increased sales, the suggestion that skill shortages may lead to reduced sales is clearly not supported by our analysis. What remains is the plausible proposition that simpler skill shortages are one of the 
results of business growth, with strong product demand, expanding in volume, or with production deepening in the use of technology and skilled labour. In this sense, simple skill shortages can be regarded as a marker of firm success.

\section{Conclusion}

The central finding of this paper is that skill shortages are a complex labour market phenomenon. Complexity, especially in the causes of skill shortages, has been a recurring theme in our analysis and proves to be an essential element in understanding how skill shortages work and how they are related to business performance. We find that some industries, such as Agriculture and Construction, are susceptible to complex skill shortages, while in others, such as Wholesale and Retail Trade and Property and Business Services, their incidence is lower.

The responses to skill shortages are also complex. Most businesses address skill shortages through better utilisation of their core workforce (e.g. longer hours, better pay and conditions, and internal training), while some employ peripheral strategies (e.g. outsourcing and short-term contracts). A small, but still significant, proportion of businesses reduce output. The interaction between complexity in the causes of and responses to skill shortages is shown to be empirically relevant in our analysis, with some response types being more sensitive to complex causes. The argument we have made from our empirical estimations is that some responses (e.g. longer hours) are utilised where there are simple causes of skill shortages, while others (e.g. reduced output) are only activated when multiple causes are encountered. Building this argument further is our evidence about the persistence of skill shortages, which shows that simple skill shortages are more likely to resolve quickly than complex ones.

Our analysis also demonstrates that the complexity of skill shortages influences their relationship to short-run business performance. Simple skill shortages are associated with favourable or improving sales performance, whereas complex skill shortages are not found to have discernible effects, when compared to firms without skill shortages. These comparisons underpin novel conclusions. Instead of being a problem, simpler skill shortages appear to be a marker of success. The businesses that report simple skill shortages are expanding and have the properties that we expect successful firms to exhibit. This does not mean that simple skill shortages are without economic costs, 
but rather that the costs are likely to be manageable in the light of expanding sales volumes and a stronger market presence for the businesses that encounter them.

Our data do not allow us to determine whether the lack of an empirical relationship between complex skill shortages and business performance is a reflection of the narrow definition of skill shortages, the small cell sizes used for making comparisons, or because there is no empirical relationship to be found. However, the finding that businesses with very complex skill shortages are the only ones to respond by reducing outputs or production, leads us to favour the possibility that there is a negative relationship between skill shortage complexity and business performance. We do not know whether this response means that firms have reduced their actual output, or that they believe potentially higher output has been foregone because of the skill shortage. There is some tension in our results between, on the one hand, the finding that complex skill shortages can lead to reduced output, and, on the other hand, the lack of clear evidence about the effects of complex skill shortages on firm performance as measured by the change in sales. Resolving this tension will be a useful direction for further research, once additional data from the fourth and fifth waves of the BLD become available. 


\section{References}

ABS [Australian Bureau of Statistics] 2009, Technical Manual, Business Longitudinal Database, Expanded Confidentialised Unit Record File [CURF], Australia, 2004-05, 2005-06 and 2006-07, ABS catalogue no.8168.0.55.002, Canberra.

ABS 2011, Labour Force, Australia, Time Series Spreadsheets, Table 01: Labour Force Status by Sex - Trend, ABS catalogue no.6202.0, Canberra. Available at http://www.abs.gov.au (Accessed 30 September 2011).

Backes-Gellner, U \& Tuor, SN 2010, 'Avoiding Labour Shortages by Employer Signaling - On the Importance of Good Work Climate, and Labor Relations', Industrial and Labor Relations Review, vol.63, no.2, pp.271-285.

Coelli, M \& Wilkins, R 2008, 'Are Skill Shortages a Constraint on Increasing Employment in Australia?’ Australian Economic Review, vol.41, no.3, pp.310-322.

Deegan, B 2008, 'Visa Sub-Class 457 Integrity Review, Final Report', October.

Green, F, Machin, S \& Wilkinson, D 1998, 'The Meaning and Determinants of Skill Shortages', Oxford Bulletin of Economics and Statistics, vol.60, no.2, pp.165-187.

Haskel, J \& Martin, C 1993a, ‘The Causes of Skill Shortages in Britain', Oxford Economic Papers, vol.45, pp.573-588.

Haskel, J \& Martin, C 1993b, 'Do Skill Shortages reduce Productivity? Theory and Evidence for the UK', Economic Journal, vol.103, no.417, pp.386-394.

Haskel, J 2001, 'Technology, Wages and Skill Shortages: Evidence from UK Microdata', Oxford Economic Papers, vol.53, no.4, pp.642-658.

Junankar, PN 2009, ‘Was there a Skill Shortage in Australia?’ IZA Discussion Paper no.4651, December.

Mavromaras, K, Oguzoglu, U \& Webster, E 2007, 'Skill Shortages and the Absence of Wage Pressure', Report for the Australian Government Department of Employment and Workplace Relations, Melbourne Institute of Applied Economic and Social Research, Project 6/2006, September.

Mitchell, W \& Quirk, V 2005, 'Skill Shortages in Australia: Concepts and Reality', Centre of Full Employment and Equity Working Paper no.05-16, University of Newcastle, November.

Oliver J. M. and Turton J. R., Is there a Shortage of Skilled Labour?, British Journal of Industrial Relations, 20(2), 1982, pp. 195-200.

Richardson, S 2007, 'What is a Skill Shortage?’ National Centre for Vocational Education Research, Adelaide.

Shah, C \& Burke, G 2005, 'Skill Shortages: Concepts, Measurement, and Policy Responses’, Australian Bulletin of Labour, vol.31, no.1, pp.44-71.

Stevens, PA 2007, 'Skill Shortages and Firms’ Employment Behaviour', Labour Economics, vol.14, no.2, pp.231-250. 
Table 1: Incidence of Skill Shortages by Main Industry of Operation, Weighted Row Percentages

Did this business have skill shortages during 2004/05?

\begin{tabular}{lcrr} 
& No & Yes & Total \\
\hline Agriculture, forestry, and fishing & 92 & 8 & 100 \\
Mining & 89 & 11 & 100 \\
Manufacturing & 87 & 13 & 100 \\
Construction & 83 & 17 & 100 \\
Wholesale trade & 93 & 7 & 100 \\
Retail trade & 90 & 10 & 100 \\
Accommodation, cafes and restaurants & 81 & 19 & 100 \\
Transport and storage & 92 & 8 & 100 \\
Communication services & 89 & 11 & 100 \\
Property and business services & 96 & 4 & 100 \\
Cultural and recreational services & 92 & 8 & 100 \\
Personal and other services & 81 & 19 & 100 \\
Total & 90 & 10 & 100 \\
\hline
\end{tabular}


Table 2: Causes of Skill Shortages (Multiple Responses Permitted)

Percentage of businesses with skill shortages

Cause of skill shortage

Specialist knowledge required 59

$\begin{array}{lr}\text { Unsure of long term demand for products or service } & 28\end{array}$

$\begin{array}{ll}\text { Recruitment too slow } & 27\end{array}$

$\begin{array}{ll}\text { Wages or salary costs too high for the business } & 26\end{array}$

Lack of availability of adequate training $\quad 23$

$\begin{array}{lr}\text { Geographic location of business } & 13\end{array}$

\begin{tabular}{lr} 
Other (please specify) & 8 \\
\hline
\end{tabular}

Number of causes reported

$\begin{array}{ll}\text { Two } & 33\end{array}$

\begin{tabular}{ll} 
Three or more & 20 \\
\hline
\end{tabular} 
Table 3: Responses to Skill Shortages (Multiple Responses Permitted)

Percentage of businesses with skill shortages

Response to skill shortage

Existing workforce worked longer hours $\quad 49$

Subcontracted or outsourced work to other businesses $\quad 31$

$\begin{array}{ll}\text { More use of on-the-job or internal training of staff } & 27\end{array}$

$\begin{array}{ll}\text { Reduced outputs or production } & 20\end{array}$

$\begin{array}{ll}\text { Wages, salaries and/or conditions increased } & 16\end{array}$

$\begin{array}{ll}\text { Employed workers on short-term contracts } & 11\end{array}$

Other (please specify) $\quad 8$

\begin{tabular}{ll} 
More use of external training of staff & 7 \\
\hline
\end{tabular}

Number of responses reported

One $\quad 54$

$\begin{array}{ll}\text { Two } & 33\end{array}$

\begin{tabular}{ll} 
Three or more & 13 \\
\hline
\end{tabular} 
Table 4: Probit Estimation of Skill Shortage Incidence

\begin{tabular}{|c|c|c|}
\hline & $\mathrm{dF} / \mathrm{dx}$ & $\mathbf{P}>|\mathbf{z}|$ \\
\hline \multicolumn{3}{|c|}{ Industry (Reference category: Manufacturing) } \\
\hline Agriculture, Forestry and Fishing & 0.147 & 0.000 \\
\hline Mining & 0.043 & 0.414 \\
\hline Construction & 0.201 & 0.000 \\
\hline Wholesale Trade & -0.067 & 0.051 \\
\hline Retail Trade & -0.011 & 0.786 \\
\hline Accommodation, Cafes and Restaurants & 0.069 & 0.099 \\
\hline Transport and Storage & 0.044 & 0.322 \\
\hline Communication Services & 0.036 & 0.481 \\
\hline Property and Business Services & -0.041 & 0.330 \\
\hline Cultural and Recreational Services & -0.063 & 0.137 \\
\hline Personal and Other Services & 0.201 & 0.000 \\
\hline \multicolumn{3}{|c|}{ Business size (Reference category: Fewer than five employees) } \\
\hline 5-19 employees & 0.161 & 0.000 \\
\hline 20-199 employees & 0.258 & 0.000 \\
\hline Single decision-maker & 0.033 & 0.082 \\
\hline Natural logarithm of total sales & 0.008 & 0.215 \\
\hline \multicolumn{3}{|c|}{ Market structure (Reference category: No competitors) } \\
\hline One or two competitors & 0.131 & 0.001 \\
\hline Three or more competitors & 0.139 & 0.000 \\
\hline \multicolumn{3}{|c|}{ Type of legal organisation (Reference category: Registered company) } \\
\hline Sole proprietor & 0.017 & 0.614 \\
\hline Partnership & -0.026 & 0.336 \\
\hline Trusts; Other Unincorporated Entity & -0.012 & 0.618 \\
\hline \multicolumn{3}{|c|}{ Years of operation (Reference category: 20 years or more) } \\
\hline Less than 5 years & 0.021 & 0.441 \\
\hline 5 to less than 10 years & -0.022 & 0.384 \\
\hline 10 to less than 20 years & 0.004 & 0.867 \\
\hline Business has a web presence & 0.016 & 0.455 \\
\hline Business operated at multiple locations & 0.023 & 0.339 \\
\hline Observed P & \multicolumn{2}{|l|}{0.210} \\
\hline Predicted P & \multicolumn{2}{|l|}{0.173} \\
\hline Sample size & \multicolumn{2}{|l|}{1941} \\
\hline Pseudo R2 & \multicolumn{2}{|l|}{0.130} \\
\hline
\end{tabular}

Note: Values of the dependent variable are: $0=$ No skill shortage; $1=$ Skill shortage. 
Table 5: Ordered Probit Estimation of the Number of Skill Shortage Causes

\begin{tabular}{|c|c|c|c|c|}
\hline & Coefficient & $\mathbf{P}>|\mathbf{z}|$ & $\begin{array}{r}\text { Lower bound } \\
\text { confidence } \\
\text { interval }\end{array}$ & $\begin{array}{r}\text { Upper bound } \\
\text { confidence } \\
\text { interval }\end{array}$ \\
\hline \multicolumn{5}{|c|}{ Industry (Reference category: Manufacturing) } \\
\hline Agriculture, Forestry and Fishing & 0.488 & 0.000 & 0.271 & 0.704 \\
\hline Mining & 0.181 & 0.335 & -0.188 & 0.550 \\
\hline Construction & 0.490 & 0.001 & 0.206 & 0.773 \\
\hline Wholesale Trade & -0.249 & 0.076 & -0.525 & 0.027 \\
\hline Retail Trade & -0.096 & 0.534 & -0.399 & 0.207 \\
\hline Accommodation, Cafes and Restaurants & 0.207 & 0.148 & -0.073 & 0.487 \\
\hline Transport and Storage & 0.217 & 0.156 & -0.083 & 0.518 \\
\hline Communication Services & 0.179 & 0.302 & -0.161 & 0.519 \\
\hline Property and Business Services & -0.152 & 0.388 & -0.498 & 0.194 \\
\hline Cultural and Recreational Services & -0.291 & 0.107 & -0.644 & 0.062 \\
\hline Personal and Other Services & 0.525 & 0.000 & 0.248 & 0.802 \\
\hline \multicolumn{5}{|c|}{ Business size (Reference category: Fewer than five employees) } \\
\hline 5-19 employees & 0.590 & 0.000 & 0.413 & 0.767 \\
\hline 20-199 employees & 0.784 & 0.000 & 0.550 & 1.019 \\
\hline Single decision-maker & 0.113 & 0.096 & -0.020 & 0.246 \\
\hline Natural logarithm of total sales & 0.028 & 0.208 & -0.016 & 0.072 \\
\hline \multicolumn{5}{|c|}{ Market structure (Reference category: No competitors) } \\
\hline One or two competitors & 0.469 & 0.000 & 0.222 & 0.716 \\
\hline Three or more competitors & 0.565 & 0.000 & 0.368 & 0.763 \\
\hline Cut 1 & 2.081 & - & 1.736 & 2.425 \\
\hline Cut 2 & 2.463 & - & 2.115 & 2.812 \\
\hline Cut 3 & 2.908 & - & 2.554 & 3.263 \\
\hline Sample size & & 1941 & & \\
\hline Pseudo R2 & & 0.081 & & \\
\hline
\end{tabular}

Note: Values of the dependent variable are: $0=$ No skill shortage; $1=$ One cause of skill shortage; $2=$ Two causes; $3=$ Three or more causes. 
Table 6: Probit Estimations of the Different Responses to Skill Shortages

\begin{tabular}{|c|c|c|c|c|c|c|c|c|c|c|c|c|}
\hline & \multicolumn{2}{|c|}{ Longer hours } & \multicolumn{2}{|c|}{ Outsource work } & \multicolumn{2}{|c|}{ Internal training } & \multicolumn{2}{|c|}{ Reduce output } & \multicolumn{2}{|c|}{ Raise wages } & \multicolumn{2}{|c|}{ Short-term contract } \\
\hline & $\mathrm{dF} / \mathrm{dx}$ & $\mathrm{P}>|\mathrm{z}|$ & $\mathrm{dF} / \mathrm{dx}$ & $\mathrm{P}>|\mathrm{z}|$ & $\mathrm{dF} / \mathrm{dx}$ & $\mathrm{P}>|\mathrm{z}|$ & $\mathrm{dF} / \mathrm{dx}$ & $\mathrm{P}>|\mathrm{z}|$ & $\mathrm{dF} / \mathrm{dx}$ & $\mathrm{P}>|\mathrm{z}|$ & $\mathrm{dF} / \mathrm{dx}$ & $\mathrm{P}>|\mathrm{z}|$ \\
\hline \multicolumn{13}{|c|}{ Number of skill shortage causes (Reference category: One cause) } \\
\hline Two causes & 0.140 & 0.016 & 0.108 & 0.049 & 0.064 & 0.284 & 0.046 & 0.391 & 0.183 & 0.001 & 0.062 & 0.158 \\
\hline Three or more causes & 0.205 & 0.001 & 0.229 & 0.000 & 0.105 & 0.094 & 0.238 & 0.000 & 0.213 & 0.000 & 0.141 & 0.003 \\
\hline \multicolumn{13}{|c|}{ Business size (Reference category: Fewer than five employees) } \\
\hline 5-19 employees & 0.125 & 0.052 & -0.044 & 0.442 & 0.182 & 0.007 & -0.123 & 0.019 & 0.200 & 0.001 & 0.030 & 0.502 \\
\hline 20-199 employees & 0.043 & 0.518 & 0.035 & 0.547 & 0.283 & 0.000 & -0.104 & 0.059 & 0.195 & 0.003 & 0.017 & 0.707 \\
\hline \multicolumn{13}{|c|}{ Market structure (Reference category: No competitors) } \\
\hline One or two competitors & -0.024 & 0.824 & 0.164 & 0.102 & 0.090 & 0.417 & -0.029 & 0.747 & 0.027 & 0.774 & -0.001 & 0.987 \\
\hline Three or more competitors & 0.049 & 0.584 & 0.046 & 0.549 & 0.091 & 0.313 & -0.017 & 0.819 & 0.041 & 0.588 & -0.015 & 0.779 \\
\hline \multicolumn{13}{|c|}{ Sector (Reference category: Primary sector) } \\
\hline Secondary sector & 0.083 & 0.243 & 0.034 & 0.588 & 0.010 & 0.888 & -0.040 & 0.505 & -0.007 & 0.907 & -0.070 & 0.082 \\
\hline Tertiary sector & -0.034 & 0.586 & -0.046 & 0.390 & 0.073 & 0.245 & -0.070 & 0.189 & 0.008 & 0.891 & -0.095 & 0.017 \\
\hline Observed P & \multicolumn{2}{|c|}{0.553} & \multicolumn{2}{|c|}{0.265} & \multicolumn{2}{|c|}{0.400} & \multicolumn{2}{|c|}{0.258} & \multicolumn{2}{|c|}{0.268} & \multicolumn{2}{|l|}{0.138} \\
\hline Predicted P & \multicolumn{2}{|c|}{0.555} & \multicolumn{2}{|c|}{0.255} & \multicolumn{2}{|c|}{0.394} & \multicolumn{2}{|c|}{0.246} & \multicolumn{2}{|c|}{0.252} & \multicolumn{2}{|l|}{0.124} \\
\hline Sample size & \multicolumn{2}{|c|}{407} & \multicolumn{2}{|c|}{407} & \multicolumn{2}{|c|}{407} & \multicolumn{2}{|c|}{407} & \multicolumn{2}{|c|}{407} & \multicolumn{2}{|l|}{407} \\
\hline Pseudo R2 & \multicolumn{2}{|c|}{0.038} & \multicolumn{2}{|c|}{0.049} & \multicolumn{2}{|c|}{0.046} & \multicolumn{2}{|c|}{0.060} & \multicolumn{2}{|c|}{0.061} & \multicolumn{2}{|l|}{0.059} \\
\hline
\end{tabular}

Note: Values of the dependent variables are: $1=$ Yes and $0=\mathrm{No}$, for each of the responses to skill shortages. 
Table 7: Probit Estimations of Skill Shortage Persistence

Lack of skilled persons hampered business performance

During 2005/06

During 2006/07

\begin{tabular}{lcccc} 
& $\begin{array}{c}\text { During 2005/06 } \\
\mathrm{dF} / \mathrm{dx}\end{array}$ & $\mathrm{P}>|\mathrm{z}|$ & $\begin{array}{c}\text { During 2006/07 } \\
\mathrm{dF} / \mathrm{dx}\end{array}$ & $\mathrm{P}>|\mathrm{z}|$ \\
\hline Number of skill shortage causes (Reference category: & No skill shortage) & & & \\
One cause & 0.212 & 0.000 & 0.104 & 0.002 \\
Two causes & 0.259 & 0.000 & 0.205 & 0.000 \\
Three or more causes & 0.345 & 0.000 & 0.402 & 0.000
\end{tabular}

Business size (Reference category: Fewer than five employees)

$\begin{array}{lllll}\text { 5-19 employees } & 0.057 & 0.010 & 0.093 & 0.000 \\ \text { 20-199 employees } & 0.115 & 0.000 & 0.139 & 0.000\end{array}$

Market structure (Reference category: No competitors)

One or two competitors

0.077

$0.034 \quad 0.017$

0.633

Three or more competitors

0.075

0.002

0.069

0.007

Industry (Reference category: Manufacturing)

Agriculture, Forestry and Fishing

$-0.025$

0.356

$-0.059$

0.034

Mining

$-0.065$

0.155

$-0.005$

0.918

Construction

$-0.033$

0.372

0.336

Wholesale Trade

$-0.049$

0.103

0.043

0.366

Retail Trade

$-0.041$

0.240

$-0.030$

0.075

Accommodation, Cafes and Restaurants

$-0.042$

0.243

0.145

Transport and Storage

$-0.018$

0.643

0.939

Communication Services

$-0.059$

0.151

0.202

Property and Business Services

$-0.040$

0.312

0.445

Cultural and Recreational Services

$-0.001$

0.971

0.759

Personal and Other Services

$-0.009$

0.817

0.150

\begin{tabular}{lcc}
\hline Observed P & 0.175 & 0.174 \\
Predicted P & 0.147 & 0.143 \\
Sample size & 1740 & 1601 \\
Pseudo R2 & 0.126 & 0.140 \\
\hline
\end{tabular}

Note: Values of the dependent variables are: 1=Lack of skilled persons hampered business performance during 2005/06 and (or) 2006/07; 0=Lack of skilled persons did not hamper business performance. 
Table 8: Ordinary Least Squares Estimation of the Change in Total Sales, 2004/05 to 2005/06

\begin{tabular}{|c|c|c|}
\hline & Coeff. & $\mathbf{P}>|\mathbf{t}|$ \\
\hline \multicolumn{3}{|c|}{ Number of skill shortage causes (Reference category: No skill shortage) } \\
\hline One cause & 0.132 & 0.051 \\
\hline Two causes & -0.025 & 0.807 \\
\hline Three or more causes & 0.019 & 0.830 \\
\hline \multicolumn{3}{|c|}{ Business size (Reference category: Fewer than five employees) } \\
\hline 5-19 employees & 0.084 & 0.119 \\
\hline 20-199 employees & 0.074 & 0.174 \\
\hline \multicolumn{3}{|c|}{ Market structure (Reference category: No competitors) } \\
\hline One or two competitors & 0.179 & 0.039 \\
\hline Three or more competitors & 0.113 & 0.105 \\
\hline \multicolumn{3}{|l|}{ Industry (Reference category: Manufacturing) } \\
\hline Agriculture, Forestry and Fishing & 0.078 & 0.314 \\
\hline Mining & -0.004 & 0.982 \\
\hline Construction & 0.041 & 0.649 \\
\hline Wholesale Trade & -0.083 & 0.346 \\
\hline Retail Trade & -0.039 & 0.634 \\
\hline Accommodation, Cafes and Restaurants & -0.063 & 0.618 \\
\hline Transport and Storage & 0.080 & 0.380 \\
\hline Communication Services & 0.178 & 0.069 \\
\hline Property and Business Services & -0.032 & 0.794 \\
\hline Cultural and Recreational Services & -0.122 & 0.143 \\
\hline Personal and Other Services & -0.033 & 0.779 \\
\hline Regression constant & -0.203 & 0.024 \\
\hline Sample size & 1825 & \\
\hline Pseudo R2 & 0.012 & \\
\hline
\end{tabular}

Note: Dependent variable is the difference between the natural logarithms of total sales in 2005/06 and 2004/05, as reported to the Australian Taxation Office. 


\footnotetext{
${ }^{1}$ This section draws on information provided in ABS (2009).

2 'Panel Two', initiated in 2005/06, has information for 3432 firms but is not analysed in this paper.

${ }^{3}$ We use Ordered Probit estimation because it does not make any assumptions about the intensity of differences between the numbers of causes reported. We cannot know whether a firm that reports two causes of skill shortages faces a problem that is doubly as complex as a firm that reported one cause (or half as complex as a firm that reported four causes). The Ordered Probit simply assumes that 1 is less than 2, which is less than 3 , and so on. This is a far less restrictive assumption than the usual linear estimator, and adds to the confidence that we can place on the results.

${ }^{4}$ We do not present or discuss in any detail the results for two of the response categories - 'more use of external training' and 'other (please specify)' - because their sample sizes are simply too small to generate statistically trustworthy estimates. Both responses have very low observed frequencies (each was selected by 35 firms).

${ }^{5}$ Because our estimating sample for this part of the analysis is restricted to the 407 firms that reported skill shortages, we have reduced the full set of industry dummy variables to a three-sector typology, where the: 'Primary sector' is Agriculture, Forestry and Fishing and Mining; 'Secondary sector' is Manufacturing and Construction; and 'Tertiary sector' is all remaining industries covered by the BLD.
} 